\title{
Mobile AC/DC test device for electric vehicle charging infrastructure communication
}

\author{
Lukas Baum · Sahar Darvish · Detlef Schulz
}

Received: 28 June 2021 / Accepted: 24 January 2022 / Published online: 8 March 2022

(C) The Author(s) 2022

\begin{abstract}
The large-scale deployment of charging infrastructure poses challenges to the distribution grid stability. In Hamburg, the project Electrify Buildings for Electric Vehicles (ELBE) implements and tests a demand side management communication protocol that allows the distribution grid operator to reduce the charging power of electric vehicle charging stations if necessary. For this purpose, a test device capable of testing the signal chain as well as a real load reduction is presented for DC charging infrastructure. The standardized high-level communication protocols are described. With the charger's power electronics located in the DC charging station, the need for a battery emulation arises, which is also discussed. Finally, a novel concept for a mobile and modular test setup for combined testing signal and real load reduction of $\mathrm{AC}$ and DC charging infrastructure is presented.
\end{abstract}

Keywords Electric vehicle charging infrastructure Electric mobility - DC charging infrastructure . Demand side management . Power line communication

\section{Mobiles AC/DC-Testgerät für Ladeinfrastruktur- Kommunikation in der Elektromobilität}

Zusammenfassung Der flächendeckende Aufbau von Ladeinfrastruktur stellt Herausforderungen an die Stabilität des Verteilnetzes. In Hamburg implementiert und testet das Projekt Electrify Buildings for Electric Vehicles (ELBE) ein Demand Side Management-Kom-

\footnotetext{
L. Baum $(\bowtie) \cdot$ S. Darvish $\cdot$ D. Schulz

Department of Electrical Power Systems, Faculty of Electrical Engineering, Helmut Schmidt University/University of the Bundeswehr Hamburg, Holstenhofweg 85, 22043 Hamburg, Germany

lukas.baum@hsu-hh.de
}

munikationsprotokoll, das dem Verteilnetzbetreiber ermöglicht, die Ladeleistung von ElektrofahrzeugLadestationen bei Bedarf zu reduzieren. Dazu wird ein Testgerät vorgestellt, das sowohl die Signalkette als auch eine reale Lastreduzierung für die DCLadeinfrastruktur testen kann. Eingangs werden die standardisierten High Level-Kommunikationsprotokolle beschrieben. Zudem wird die Notwendigkeit einer Batterieemulation diskutiert, da sich die Leistungselektronik des Ladegeräts in der DC-Ladestation befindet. Abschließend wird ein neuartiges Konzept für einen mobilen und modularen Testaufbau zur kombinierten Testsignal- und realen Lastreduzierung von AC- und DC-Ladeinfrastruktur vorgestellt.

Schlüsselwörter Elektrofahrzeug-Ladeinfrastruktur . Elektromobilität · DC-Ladeinfrastruktur · Demand Side Management · Power Line Communication

\section{Introduction}

The increasing share of electrified mobility imposes significant challenges to the stability of the electric grid. Managing the power demand created by increasingly powerful electric vehicle charging infrastructure is and will be a method to avoid overloading of power generation and transmission infrastructure. Using demand-side management will allow for better utilization of the existing infrastructure and thus faster growth and adoption of electric mobility [1-3].

In 2018 a consortium around the City of Hamburg started the project Electrify Buildings for Electric Vehicles (ELBE) that supports the large-scale deployment of charging infrastructure for electric vehicles (EV) controllable by the local distribution system operator (DSO) [4]. A communication protocol using open automated demand response (OpenADR) with ELBE specifications [5], implemented between DSO and the 
charge point operator (CPO), is used to manage the peak power demand [6].

Most of the planned charging infrastructure installed in the mentioned project's scope is so-called AC charging infrastructure utilizing onboard chargers. Nonetheless, also DC charging infrastructure is considered. Here, the heavier high-power charger or $\mathrm{AC} / \mathrm{DC}$-converter including the charge-controller is located inside the charge point.

The test cases in project ELBE are limited to validating the grid-friendly load reduction. In the project ELBE, both the signal path of the load reduction command and the resulting reduction of electrical charging power are supposed to be tested. A test of other electrical and signal properties is not the project's scope. Thus, to avoid an overcomplicated test tool and to "keep it simple", the test setup is designed for the mentioned specific test cases. A suitable test setup for AC charging infrastructure including real AC load testing is presented in [6]. In this work, a new test setup usable for testing both the communication interface and the electric characteristics under real loading of DC charging infrastructure is presented. The standardized communication protocols for Mode-4, a test setup including a high-level power line communication (PLC) interface and emulation of an EV, and a concept for a mobile and grid-independent load testing device for both $\mathrm{AC}$ and DC charging infrastructure is described.

\section{Challenges charging process standardization}

Testing of charging infrastructure imposes several challenges. Firstly, a communication interface has to be established between the Electric Vehicle Com- munication Controller (EVCC) on-board the EV and the Supply Equipment Communication Controller (SECC) in the EVSE. For AC charging basic signalling according to IEC 61851-1 facilitates a $1 \mathrm{kHz}$ pulsewidth-modulated (PWM) square-wave signal on the $\mathrm{CP}$ cable connection. The PWM duty cycle and the resulting real load reduction are the relevant test parameters tested in the project ELBE for AC charging [6].

For DC or Mode-4-charging, the onboard BMS has to communicate with the charger-controller inside the charge point to request the required DC voltage and current and receive the maximum available DC voltage and current which are the relevant test parameters tested in the project ELBE for DC charging. Here, High-Level Communication (HLC) is used as a bidirectional communication link between the EVCC and the SECC. The HLC is established on the CP cable connection as power line communication (PLC) standardized in IEC 61851-23 and IEC 61851-24, based on ISO 15118 and DIN SPEC 70121. The electric signalling circuits are shown in Fig. 1.

To start the PLC from the basic signalling used for AC charging, the EVSE must set the CP-duty cycle to $5 \%$. After that, a PLC data link is established according to HomePlug Green PHY (HPGP). HPGP multiplexes onto the basic control pilot signal and is compliant with the IEEE 1901-2020 Standard for Broadband over Power Line Networks but trades high data rates for low power, low cost, and robust performance [7]. After exchanging Signal Level Attenuation Characterisation (SLAC) messages, communication layers according to UDP, IPv6, TCP, and the V2G Transfer Protocol (V2GTP) are established. V2GTP is the standard transfer protocol between the EVCC and SECC.
Fig. 1 SECC and EVCC circuits for basic signalling and HLC according to IEC $61851-1$

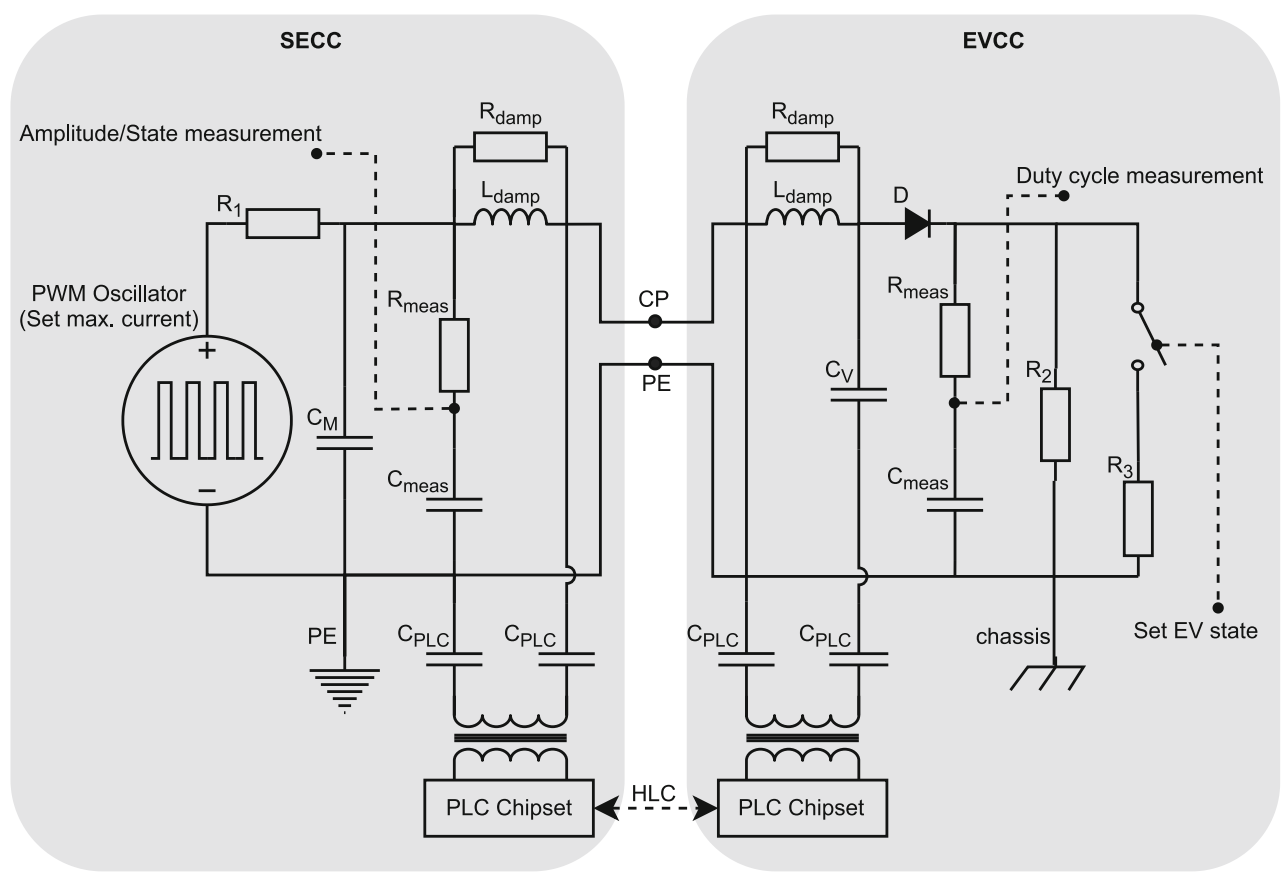


To establish and control the charging process, control messages are now exchanged with V2GTP.

After the successful communication setup phase, the identification, authentication, and authorization phase are run through, after which the chargingconnector has to be locked. Next, a sequence of exchanging target settings and charge scheduling is run through. The EV's and EVSE's maximum voltage, current, and power limits are exchanged during ChargeParameterDiscoveryRequest and -Response. Subsequently, during CableCheckRequest and -Response, the EVSE checks for cable isolation above $100 \mathrm{k} \Omega$ by applying the before communicated maximum allowed voltage. After the successful isolation check, the communication enters PreChargeRequest and -Response, where the EVSE pre-charges the cable with a maximum current of $2 \mathrm{~A}$ to the before communicated EVTargetVoltage. The EV may now close the high-voltage contactors as soon as the voltage difference between cable and battery is below $20 \mathrm{~V}$. By exchanging a PowerDeliveryRequest and -Response, EV and EVSE enter the ChargeLoop. Here the EVCC constantly sends a CurrentDemandRequest including a target current and target voltage as requested by the on-board charge controller or BMS, while the SECC constantly sends a CurrentDemandResponse including the momentary current and power measurements as well as the maximum available current, voltage, and power.

The content of the SECC's CurrentDemandResponse is the relevant test parameter to be tested in the project ELBE, as it must be set according to the maximum allowed load as communicated by the DSO. Additionally, a charging power reduction to the maximum allowed load power has to be observed, even if the power demand request by the EV is above.

\section{Laboratory test setup}

To test if load reduction events sent by the DSO are correctly transmitted and executed by the charge point, a simulation of an EV conducting Mode-4 charging is set up. This setup includes, among other components, an EVCC as well as the emulation of a battery.

Since the test of the communication protocol itself is not the project's scope, a readily available communication controller certified for charge communication according to ISO 15118, DIN SPEC 70121, and IEC 61851 is used as EVCC.

According to IEC 62196, DC power supply combined charging system (CCS), system C, configuration FF is limited to $1000 \mathrm{~V}$ and $400 \mathrm{~A}$. The ELBE specifications define the so-called LOAD_DISPATCH signal as either the maximum allowed power at the grid-connection point in kilowatt or as a reduction to $50 \%$ of the installed charging power. In any case, a minimum charging current of $8 \mathrm{~A} \mathrm{[5]}$ or $5.54 \mathrm{~kW}$, assuming 3 -phase AC charging, is guaranteed. The minimal test design does thus include the test of a load reduction from any load to minimum load.

Most state-of-the-art EVs use lithium-ion battery cells of different cell chemistries. In rest, the electric potential of the cell can be measured as the Open Circuit Voltage (OCV), which is dependent on the State of Charge (SoC) of the cell. To charge the cell, a voltage $U_{\text {charger }}$ higher than the OCV $U_{\text {ocv }}$ has to be applied to the cell, resulting in a current flow. The chemical reactions do not occur infinitely fast; thus, the resulting currents during charging and discharging are limited and, among other factors, dependent on the over- or undervoltage applied to the cell. The most simple equivalent circuit model of a battery cell is, therefore, an ideal voltage source representing the OCV and a resistance representing the internal chemical resistance of the cell [8]. The basic equivalent circuit model is shown left in Fig. 2.

The emulation of the EV's battery in its most straightforward way thus consists of a bidirectional DC voltage source, as well as an ohmic resistor. This setup is shown right in Fig. 2. The voltage source or current sink must be controlled to have a constant output voltage. Dependent on the voltage difference $\Delta U_{\text {overvoltage }}$ between the applied voltage $U_{\text {charger }}$ by the EVSE and the voltage $U_{\text {ocv }}$ of the DC source, that is applied to the resistance $R_{\text {int }}$, the charging current $I_{\text {charge }}$ is given by Ohm's law as (1).

$$
I_{\text {charge }}=\Delta U_{\text {overvoltage }} R_{\text {int }}=R_{\text {int }}\left(U_{\text {charger }}-U_{\text {ocv }}\right)
$$

For the laboratory test setup shown in Fig. 3 and 4, a bidirectional regenerative DC source/sink with a maximum voltage of $500 \mathrm{~V}$ and a maximum source and sink power of $15 \mathrm{~kW}$ was used and serially connected to a $100 \mathrm{~m} \Omega$ resistor $R_{\text {int }}$. This setup is sufficient to test most DC charging stations that support voltages up to $480 \mathrm{~V}$. $15 \mathrm{~kW}$ of sink power is sufficient to test a reduction to the minimum guaranteed power of $5.54 \mathrm{~kW}$, but the concept is scalable to a higher power. First tests conducted in the laboratory of the Helmut Schmidt University have shown the validity of the presented concept.

\section{Novel concept of a mobile combined AC/DC test device}

In the project ELBE, there is also the requirement for mobile testing of charging infrastructure. Both the test setups presented so far are designed for laboratory use, without any requirements for portability and autonomy. Therefore, a novel combined device for AC and DC testing using modular grid-independent dissipative loads and an auxiliary battery power supply is developed. Three dissipative electronic DC loads are used. For DC charging, they are parallel connected via coupling diodes and controlled in constant voltage mode to up to $900 \mathrm{~V} \mathrm{DC}$, which is sufficient to test even state of the art $350 \mathrm{~kW}, 800 \mathrm{~V}$ DC charging in- 
Fig. 2 Battery equivalent model and test setup

Fig. 3 Concept DC laboratory setup

Fig. 4 Laboratory setup: EV-Sim with EVCC and DC source/sink
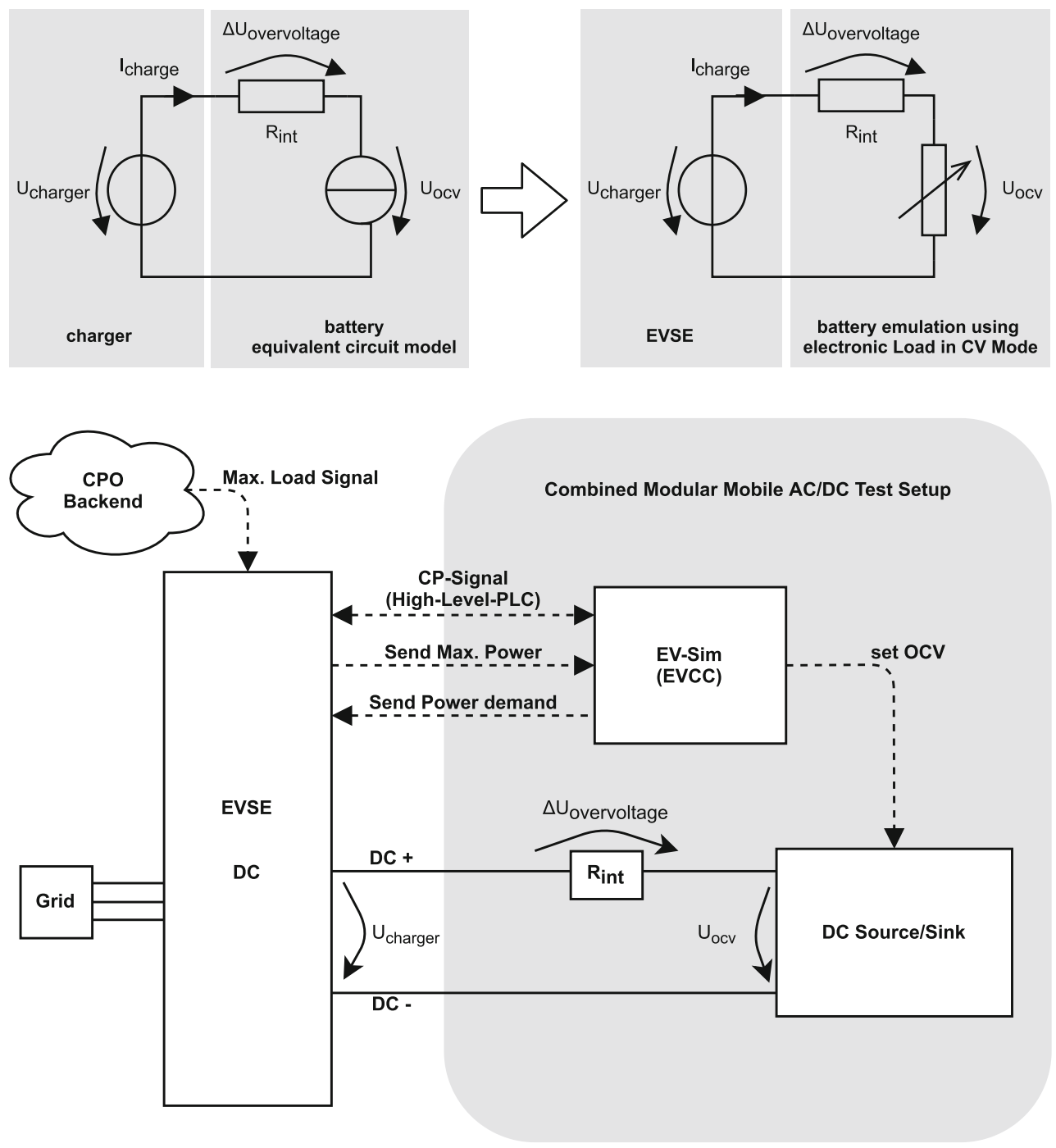

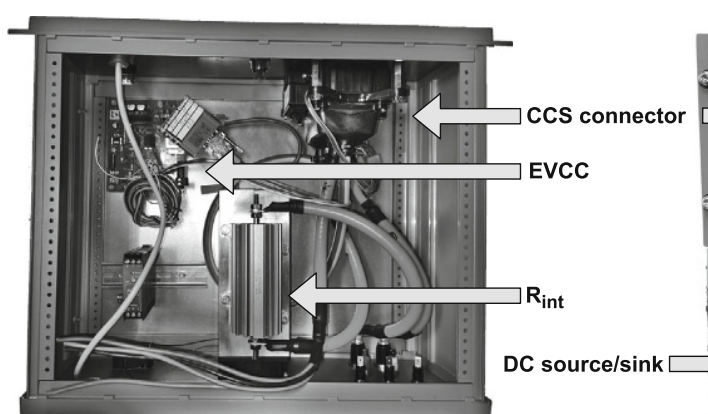

top view

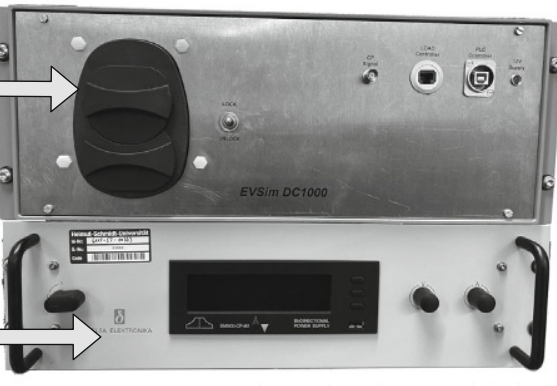

front view frastructure. A $1.2 \mathrm{kV}$ DC source is parallel connected to provide and emulate the OCV for the no-load case while establishing the DC charging process. As for the laboratory test setup, a $100 \mathrm{~m} \Omega$ ohmic resistance is connected in series. To facilitate the same electronic DC-Loads for AC charging, the AC currents are rectified using a single-phase diode bridge separately for each phase. Controlling the loads in constant resistance mode, thus controlling the current to follow the resulting rectified positive half-waves, a three-phase on-board charger with power factor correction is emulated. The described concept is shown in Fig. 5. The entire setup requires a power supply of less than $1 \mathrm{kVA}$ and is powered by a lithium battery power supply. Due to the modular nature, especially the loads, the test setup can be transported in modules of less than $30 \mathrm{~kg}$ weight or be stacked on a wheel board with a total weight of only $100-150 \mathrm{~kg}$, including $9.6 \mathrm{~kW}$ of 
Fig. 5 Concept combined AC/DC test setup

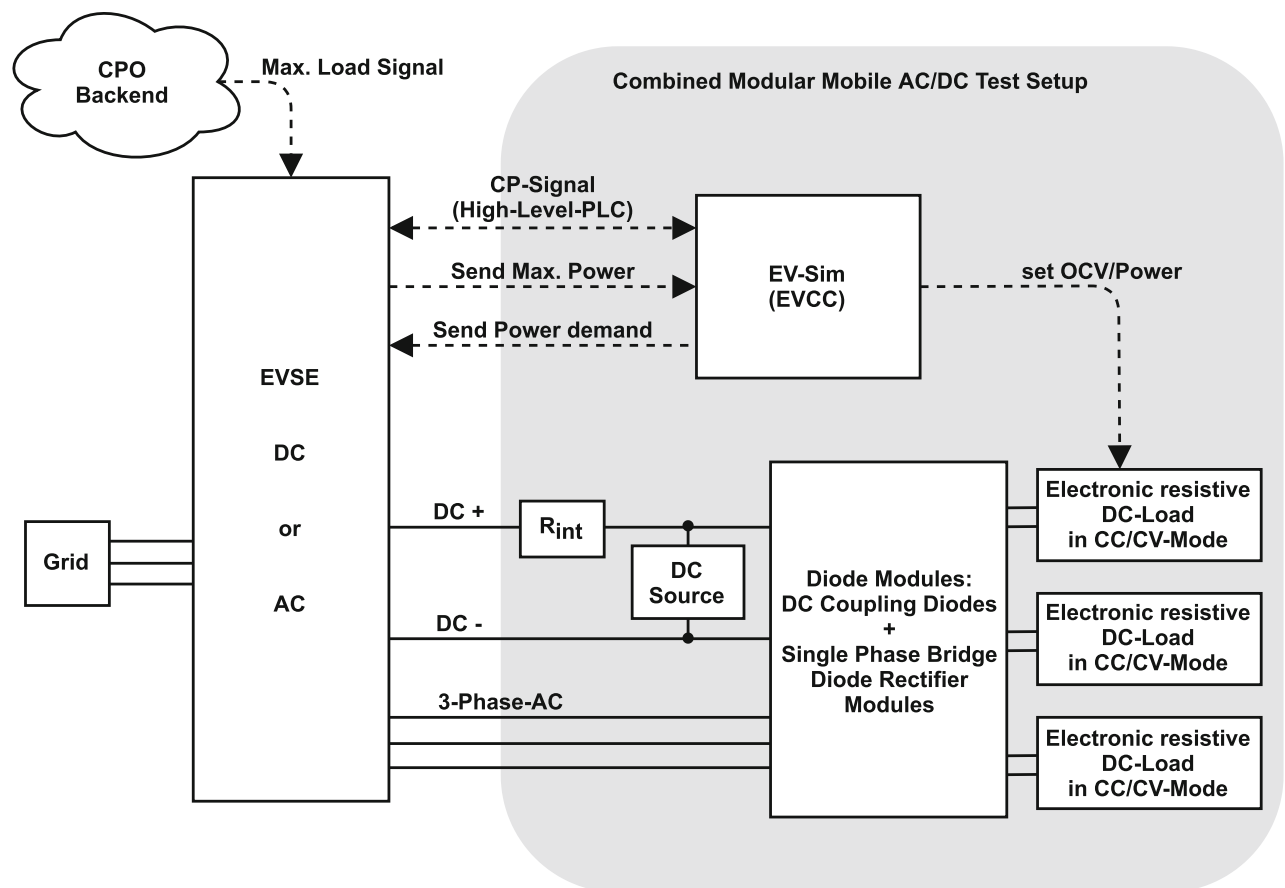

dissipative loads and approx. $90 \mathrm{~min}$ of autonomous power supply.

\section{Conclusion}

The project ELBE raises the new requirement for load testing of EV charging infrastructure. While test solutions for AC load testing of load reductions communicated over OpenADR are presented in earlier publications, a novel solution for DC testing under load was presented. For this purpose, an electric vehicle is emulated. A PLC interface for charging communication is established using a standardized EVCC. The battery is emulated using a bi-directional DC source/ sink and a resistance. This solution allows for the test of EV charging infrastructure under real loading for extended durations. The realized laboratory setup is scalable to load testing of maximum standardized charging power of $1000 \mathrm{~V}, 400 \mathrm{~A}$ if the grid connection allows. Additionally, a novel concept for a modular and mobile test setup is presented, combining the validated concepts used in the laboratory test setups for AC and DC testing. This concept will be realized and validated in the future.

Funding This work is a part of the accompanying research project for Electrify Buildings for EVs (ELBE). It is supported by the German Federal Ministry of Economic Affairs and Energy (FKZ: 01MZ18014F).

Author Contribution Conceptualization: Lukas Baum, Sahar Darvish, Detlef Schulz; Methodology: Lukas Baum, Sahar Darvish; Formal analysis and investigation: Lukas Baum; Writing_original draft preparation: Lukas Baum; Writing — review and editing: Lukas Baum, Sahar Darvish, Detlef Schulz; Fund- ing acquisition: Detlef Schulz; Resources: Detlef Schulz; Supervision: Detlef Schulz

Funding Open Access funding enabled and organized by Projekt DEAL.

Conflict of interest L. Baum, S. Darvish and D. Schulz declare that they have no competing interests.

Open Access This article is licensed under a Creative Commons Attribution 4.0 International License, which permits use, sharing, adaptation, distribution and reproduction in any medium or format, as long as you give appropriate credit to the original author(s) and the source, provide a link to the Creative Commons licence, and indicate if changes were made. The images or other third party material in this article are included in the article's Creative Commons licence, unless indicated otherwise in a credit line to the material. If material is not included in the article's Creative Commons licence and your intended use is not permitted by statutory regulation or exceeds the permitted use, you will need to obtain permission directly from the copyright holder. To view a copy of this licence, visit http://creativecommons.org/licenses/by/4.0/.

\section{References}

1. European Union (2020) International Benchmark 2020: New mobility \& road infrastructure

2. Nicholas M, Wappelhorst S (2020) Regional charging infrastructure requirements in Germany through 2030. International Council on Clean Transportation

3. Windt A, Arnhold O (2020) Ladeinfrastruktur nach 2025/2030: Szenarien für den Markthochlauf. Nationale Leitstelle Ladeinfrastruktur

4. Darvish S, Jordan R, Schulz D et al (2019) Implementation of network-friendly charging infrastructures for electric vehicles in the city of Hamburg in the ELBE project (orig.: Implementierung netzdienlicher Ladeinfrastrukturen für 
Elektrofahrzeuge in der Stadt Hamburg im Projekt ELBE) In: Schulz D (ed) Aktuelle Infrastruktur- und Technologieansätze in den Bereichen Strom- und Gasnetz, Elektromobilität und Wasserstoffwirtschaft. Hamburger Beiträge zum technischen Klimaschutz, vol 1, pp 36-39

5. Stromnetz Hamburg (2020) ELBE MVP specification v1.1: ELBE Specification for a minimum viable prototype based on OpenADR2.0b

6. Darvish S, Baum L, Grumm F et al (2020) A smart charging management interface for electric vehicles based on communication links through the electrical grid. Virtual 4th E-Mobility Power System Integration Symposium.

7. Zyren J (2015) EV combined charging system featuring homeplug green PHY. Qualcomm Technologies, Inc

8. Barcellona S, Piegari L (2017) Lithium Ion battery models and parameter identification techniques. Energies. https://doi.org/10.3390/en10122007

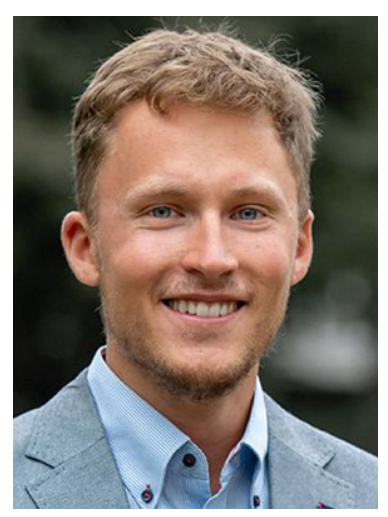

Lukas Baum, received the Bachelor of Science degree in General Engineering Science from the Hamburg University of Technology, Hamburg, Germany, in 2017, and the Master of Science degree in Electrical Power Engineering from the Chalmers University of Technology, Gothenburg, Sweden, in 2020. He is currently a research assistant with the Department of Electrical Power Systems, Helmut-Schmidt-University/ University of the Bundeswehr Hamburg, Germany. His research interests include onboard power systems and the integration of distributed modular generation and storage systems.

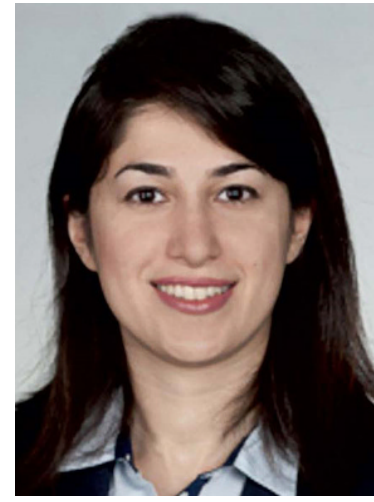

Sahar Darvish, received the Bachelor of Science degree in electrical power engineering from the University of Mazandaran, Babolsar, Iran, in 2011, and the Master of Science degree in Electrical Power Engineering from the Brandenburg University of Technology Cottbus-Senftenberg, Germany, in 2016. She is currently a research assistant with the Department of Electrical Power Systems, HelmutSchmidt-University/University of the Bundeswehr Hamburg, Germany. Her research interests include electric vehicle charging infrastructure, congestion management, and demand response.

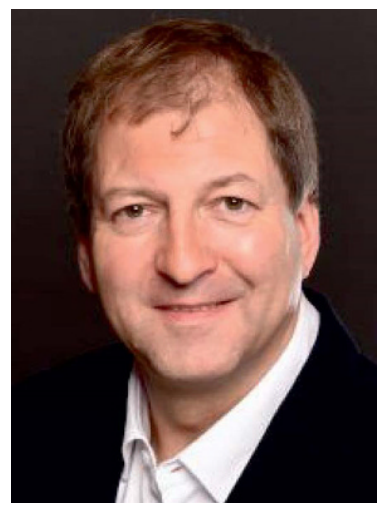

Detlef Schulz, received the Dipl.-Ing. degree in electrical engineering from the Brandenburg Technical University Cottbus, Germany, in 1997, and the Dr.-Ing. and venia legendi degree in electrical engineering from the Technical University Berlin, Germany, in 2002 and 2006, respectively. From 1997 to 1999 , he was with the $\mathrm{ABB}$ Automation Cottbus $\mathrm{GmbH}$, Germany. Since 2006, he has been a Full Professor and the Head of the Department of Electrical Power Systems, Helmut-Schmidt-University/University of the Bundeswehr Hamburg, Germany. His research interests include electrical power systems and on-board electrical systems: grid integration and grid conformity of distributed generation and electro-mobility, grid impedance measurement, grid protection and internal electrical control of fuel cells, which are pursued at DLab-Distributed Energy Laboratory. He is a member of the VDE ETG and IEEE PES and a Full Member of the Academy of Sciences and Humanities, Hamburg. 